\title{
Improving outcomes in lung cancer: the value of the multidisciplinary health care team
}

\author{
This article was published in the following Dove Press journal: \\ Journal of Multidisciplinary Healthcare \\ 30 March 2016 \\ Number of times this article has been viewed
}

\section{Eve Denton' \\ Matthew Conron ${ }^{2}$ \\ 'Allergy, Immunology and Respiratory Department, Alfred Hospital, ${ }^{2}$ Department of Respiratory and Sleep Medicine, St Vincent's Hospital, Melbourne, VIC, Australia}

Correspondence: Eve Denton Allergy, Immunology and Respiratory Department, Alfred Hospital, PO Box 315, Prahran, Melbourne, VIC 318I, Australia $\mathrm{Tel}+61390762000$

Fax +6I 39076360 I

Email Eve.denton@gmail.com

\begin{abstract}
Lung cancer is a major worldwide health burden, with high disease-related morbidity and mortality. Unlike other major cancers, there has been little improvement in lung cancer outcomes over the past few decades, and survival remains disturbingly low. Multidisciplinary care is the cornerstone of lung cancer treatment in the developed world, despite a relative lack of evidence that this model of care improves outcomes. In this article, the available literature concerning the impact of multidisciplinary care on key measures of lung cancer outcomes is reviewed. This includes the limited observational data supporting improved survival with multidisciplinary care. The impact of multidisciplinary care on other benchmark measures of quality lung cancer treatment is also examined, including staging accuracy, access to diagnostic investigations, improvements in clinical decision making, better utilization of radiotherapy and palliative care services, and improved quality of life for patients. Health service research suggests that multidisciplinary care improves care coordination, leading to a better patient experience, and reduces variation in care, a problem in lung cancer management that has been identified worldwide. Furthermore, evidence suggests that the multidisciplinary model of care overcomes barriers to treatment, promotes standardized treatment through adherence to guidelines, and allows audit of clinical services and for these reasons is more likely to provide quality care for lung cancer patients. While there is strengthening evidence suggesting that the multidisciplinary model of care contributes to improvements in lung cancer outcomes, more quality studies are needed.
\end{abstract}

Keywords: lung cancer, multidisciplinary care, mortality, tumor board, quality of life

\section{Introduction}

Lung cancer accounts for a large burden of disease worldwide, being in the top five most commonly diagnosed cancers. In 2012, more than 210,000 new cases were diagnosed in the US, 44,000 in the UK, and 10,000 in Australia. ${ }^{1-3}$ Despite being only the fourth-most commonly diagnosed malignancy in developed nations, lung cancer is the number-one cause of cancer death worldwide, responsible for 1.59 million deaths in 2012 alone. ${ }^{1,4}$ In the US alone, more than 157,000 people died from lung cancer in $2012 .^{2}$

Over the last few decades, there has been only a gradual and very modest improvement in lung cancer survival, which remains dismally low, with only $14.1 \%$ and $5 \%$ of patients diagnosed with lung cancer surviving 5 and 10 years, respectively. ${ }^{5}$ It is estimated that $89 \%$ of cases are preventable, and unlike other cancers we have not seen major improvements in lung cancer mortality over time. ${ }^{3,5}$ In addition to high disease-related mortality, lung cancer is also a major cause of morbidity, consistently rating within the top ten conditions causing the highest burden of disease. ${ }^{6}$ The high 
disease-related morbidity and mortality make improving lung cancer outcomes a high priority.

In the past two decades, multidisciplinary care - the treatment of patients via direct collaboration of specialists - has emerged as the standard of care in cancer management. ${ }^{7-11}$ In 2007, a European Union health services review committee published guidelines suggesting that "a multidisciplinary approach to cancer care is required to make the best decisions about each patient's diagnosis, treatment and support". ${ }^{12}$ In the US, the "tumor board" is a requirement for accreditation of centers providing multidisciplinary cancer care regulated by the American College of Surgeons and the Commission on Cancer; discussions must occur at least monthly, with prospective review of cases and management decisions. ${ }^{13,14}$ Through the development of guidelines and regulations such as these, multidisciplinary care has evolved into the standard of care in many parts of the world, despite a relative paucity of quality evidence that it improves survival and other outcomes in lung cancer. ${ }^{1,15,16}$

Health services research that includes studies of patterns of care in lung cancer treatment has identified measures of quality treatment in lung cancer. These include time to specialist referral, time between diagnosis and initiation of treatment, utilization of specialist investigations, including endobronchial ultrasound and positron-emission tomography, discussion at a multidisciplinary meeting (MDM) or tumor board, and access to surgery, radiotherapy, chemotherapy, and clinical trials. ${ }^{1,17-21}$ Furthermore, qualify-of-life research has identified that such factors as communication by health professionals, process streamlining, and the presence of nurse coordinators improve patient experience of the lung cancer journey. ${ }^{22,23}$ While there is limited evidence to date that multidisciplinary care improves these quality indicators of lung cancer treatment, intuitively it would seem likely to be the case. Further studies are required in this important area of health services research.

Despite the lack of evidence supporting this model of care, the utilization of multidisciplinary teams (MDTs) has increased dramatically in Europe and the US in recent times. Twenty years ago in the UK, $<20 \%$ of cancer patients were managed by an MDT; by 2004 , this number was $>80 \% .{ }^{24}$ In the US, one large observational study showed that $53.8 \%$ of physicians attended tumor boards weekly, $42 \%$ attended less often, and only $4.2 \%$ did not attend at all. ${ }^{25}$ It has become increasingly difficult to perform randomized trials to investigate the impact of multidisciplinary care, due to the difficulty in recruiting patients from centers where this model is not the standard of care. As a result, we largely rely on observational studies to evaluate the value of multidisciplinary care. Confounding the interpretation of studies investigating the role of multidisciplinary care in cancer management is the parallel introduction of improvements in therapeutics, eg, small-molecule tyrosine-kinase inhibitors that have been shown to confer survival benefits for lung cancer patients. Despite these difficulties in study design, there is an increasing body of literature suggesting that multidisciplinary care improves numerous aspects of lung cancer care, including but not limited to survival.

\section{Defining the multidisciplinary health care team}

Different definitions of multidisciplinary care exist. The most inclusive definition is of "an integrated team approach to health care in which medical and allied health care professionals consider all relevant treatment options and develop collaboratively an individual treatment plan for each patient". ${ }^{26}$ An important aspect of multidisciplinary care is an emphasis on patient-centered care and an attempt to improve the patient journey through communication, collaboration, and streamlining of diagnostics and therapeutics.

The medical members of a lung cancer MDT would typically include a respiratory physician, medical oncologist, radiation oncologist, cardiothoracic surgeon, pathologist, radiologist, and a palliative care physician. ${ }^{1,9,15,16,26-30}$ Additionally, the presence of nursing coordinators and allied health staff is considered by many necessary to coordinate and deliver the best-quality multidisciplinary care. ${ }^{27}$ An inclusive MDT should provide the best opportunity for optimal care, incorporating all involved specialties at the outset and facilitating critical discussion. ${ }^{31,32}$

\section{Leadership}

Leadership of the MDM is critical to facilitate open discussion, including any disagreements, allowing the consideration of all opinions across the specialties, not just the view of the person with the loudest voice. ${ }^{8,32}$ Good leadership is important in the discussion process and also to keep the meetings on track. It is important that the leader of the discussion is respected by all members of the MDT, and that they feel comfortable voicing their opinions. ${ }^{32}$ Furthermore, a leader can provide feedback to the MDT and audit outcomes to ensure participants are encouraged to perform at their optimum. ${ }^{8}$

\section{Communication}

Key to the process of MDT management is communication. Intuitively, communication within the MDT and 
with patients and family members should be of critical importance in the delivery of successful multidisciplinary care, but there is little evidence to support this assumption. ${ }^{8}$ With a large number of health professionals involved in a patient's care, effective communication with a patient's primary care physician is important and is generally the task of a dedicated member of the MDT. ${ }^{28}$ Patient involvement or a consumer representative at MDMs is not common practice, with $>95 \%$ of MDMs exclusively involving health professionals. ${ }^{33}$

\section{Resources}

Adequate facilities for MDMs are essential to ensure that there is effective information sharing and communication among the different specialties. ${ }^{27}$ This includes information technology that allows projection of radiology and pathology results that can be viewed by all the members of the MDT. ${ }^{26}$ Ideally, a dedicated data-management system should be available to upload information into an electronic medical record. ${ }^{26}$ For many MDMs, teleconference facilities are required to allow participation by team members who may be unable to attend the meeting in person or are located in rural or remote areas. There is evidence that teleconferencing may improve attendance at MDMs without negatively impacting patient care. ${ }^{19}$

\section{Impact of multidisciplinary care on lung cancer outcomes}

As previously discussed, measuring the effects of multidisciplinary care on outcomes in lung cancer is difficult, because of the inability to perform randomized trials and the confounding effects of more effective therapeutics on interpreting observational studies. ${ }^{8}$ The effect of multidisciplinary care is herein initially discussed in relation to the outcomes of survival and mortality, and then in relation to other measures of quality lung cancer care. These other measures include the facilitation of timely care, access to diagnostic investigations, quality of staging, treatment delivered, and completeness of ongoing surveillance and follow-up. Finally, the effect of multidisciplinary care on patient-centered outcomes, such as quality of life, is discussed. ${ }^{22}$ A summary of the key studies pertaining to multidisciplinary care and lung cancer outcomes is provided (Table 1).

\section{Survival}

There is an increasing body of evidence from observational studies involving other tumor types that multidisciplinary cancer care improves survival. In breast cancer, there is evidence that outcomes are improved in cases where surgeons operate on $>30$ cases per year in an MDT setting. ${ }^{34}$ Likewise, in a group of Scottish patients with ovarian cancer, retrospective data suggested that referral to a multidisciplinary clinic was an independent predictor of improved survival. ${ }^{35}$ There have been similar results reflected in the field of head and neck cancer, with one study finding improved survival in a group of patients who were managed in a multidisciplinary clinic versus those who were not seen in the clinic. ${ }^{36}$ One prospective study in the UK compared patients with esophageal cancer who were managed with multidisciplinary care to a historical cohort, and found that the multidisciplinary care group had less operative mortality and improved 5-year survival. ${ }^{37}$ Similar results have been seen in nonsolid organ tumors, with Davis et al demonstrating that the mortality of Hodgkin's disease was 50\% higher even when adjusted for patient age and stage among those not treated at comprehensive cancer centers where a multidisciplinary approach was the standard of care. ${ }^{38}$ In colorectal cancer, Morris et al found a statistically significant improvement in 5-year survival when there was improved adherence to guidelinebased therapy by MDTs, after adjustment for multiple other prognostic factors. ${ }^{39}$

In regard to the effect of multidisciplinary care on lung cancer survival, there remains a relative paucity of data..$^{7,10,40}$ In the absence of randomized trials, we rely on observational studies (with their recognized limitations) to provide us with evidence for multidisciplinary care conferring improved survival. In one prospective, single-center observational study, all patients with inoperable lung cancer were identified over a period of 1 year and outcomes assessed, including survival. ${ }^{7}$ While there was no significant difference in treatment received, improved survival was observed in the group discussed at an MDM in comparison to the group that was not discussed. ${ }^{7}$ The results of this study should be interpreted with caution, due to the single-center observational nature of the study, as it is possible that significant differences existed between patients discussed at the MDM and those who were not. Another retrospective cohort-based study examined patients with inoperable non-small-cell lung cancer (NSCLC) recruited from a single center in Scotland before and after the introduction of MDTs. ${ }^{10}$ It was observed that there was an increased proportion of patients staged and more chemotherapy utilized, with fewer patients receiving supportive care only in the post-MDT cohort compared to pre-MDT implementation. ${ }^{10}$ Additionally, patients post-MDT implementation had significantly improved survival, with a median survival of 6.6 months compared to 3.2 months in the 
Table I Key studies pertaining to multidisciplinary care and outcomes in lung cancer

\begin{tabular}{|c|c|c|c|c|}
\hline Study & Design & Participants & Aims & Results \\
\hline Bydder et $\mathrm{al}^{7}$ & $\begin{array}{l}\text { Prospective } \\
\text { observational } \\
\text { single center }\end{array}$ & $\begin{array}{l}98 \text { with inoperable } \\
\text { NSCLC }\end{array}$ & $\begin{array}{l}\text { Comparison of those discussed } \\
\text { and not discussed at MDT over } \\
12 \text { months }\end{array}$ & $\begin{array}{l}\text { Improved survival in those discussed at MDT } 280 \\
\text { vs } 205 \text { days }(P=0.048)\end{array}$ \\
\hline Forrest et $\mathrm{al}^{10}$ & $\begin{array}{l}\text { Retrospective } \\
\text { observational } \\
\text { single center }\end{array}$ & $\begin{array}{l}323 \text { with inoperable } \\
\text { NSCLC }\end{array}$ & $\begin{array}{l}\text { Comparison of two cohorts } \\
\text { before and after MDT } \\
\text { introduction }\end{array}$ & $\begin{array}{l}\text { Improved use of chemotherapy }(23 \% \text { vs } 7 \%) \text { and } \\
\text { survival } 6.6 \text { vs } 3.2 \text { months }(P<0.001) \text { in those after } \\
\text { introduction of MDT }\end{array}$ \\
\hline Kehl et $\mathrm{al}^{25}$ & $\begin{array}{l}\text { Prospective } \\
\text { observational } \\
\text { multicenter }\end{array}$ & $\begin{array}{l}4,620 \text { with lung or } \\
\text { colorectal cancer }\end{array}$ & $\begin{array}{l}\text { Comparison of those treated } \\
\text { by physicians attending } \\
\text { different styles of MDTs }\end{array}$ & $\begin{array}{l}\text { Regular physician tumor-board involvement was } \\
\text { associated with clinical trial participation (OR I.6, } \\
95 \% \mathrm{CI} \text { I.I-2.2) and resection rates (OR 2.9, } \\
95 \% \mathrm{Cl} \text { I.3-6.8), but not overall survival }\end{array}$ \\
\hline Salomaa et al $^{17}$ & $\begin{array}{l}\text { Retrospective } \\
\text { observational } \\
\text { single center }\end{array}$ & $\begin{array}{l}\text { I } 32 \text { lung cancer } \\
\text { hospital patients }\end{array}$ & $\begin{array}{l}\text { Examine for presence and } \\
\text { causes of delays in the diagnosis } \\
\text { and treatment of lung cancer }\end{array}$ & $\begin{array}{l}\text { Multiple reasons were found for diagnostic delays in } \\
\text { lung cancer that maybe improved by a multidisciplinary } \\
\text { approach }\end{array}$ \\
\hline Keating et $\mathrm{al}^{47}$ & Observational & $\begin{array}{l}\text { All cancer patients } \\
\text { diagnosed or treated } \\
\text { at VA hospitals }\end{array}$ & $\begin{array}{l}\text { Association of tumor boards } \\
\text { with outcomes adjusted for } \\
\text { patient and clinical parameters }\end{array}$ & $\begin{array}{l}\text { Tumor boards associated with increased radiation } \\
\text { therapy for early stage lung cancer not undergoing } \\
\text { surgery; those with stage IIIA disease not surgically } \\
\text { managed or with limited small-cell lung cancer were } \\
\text { more likely to undergo chemoradiotherapy }\end{array}$ \\
\hline Lamb et al' & $\begin{array}{l}\text { Systematic } \\
\text { review }\end{array}$ & $\begin{array}{l}37 \text { studies included, } \\
\text { most poor quality }\end{array}$ & $\begin{array}{l}\text { Assessed quality of MDT } \\
\text { care decisions }\end{array}$ & $\begin{array}{l}\text { MDTs changed cancer management in } 2 \%-52 \% \text { of } \\
\text { cases; failure to reach decision in } 27 \%-52 \% \text { cases, } \\
\text { patient preferences not discussed; multiple } \\
\text { barriers to good MDT care identified }\end{array}$ \\
\hline
\end{tabular}

Abbreviations: NSCLC, non-small-cell lung cancer; MDT, multidisciplinary team; OR, odds ratio; Cl, confidence interval; VA, US Veterans Affairs.

pre-MDT cohort. ${ }^{10}$ Criticisms of this study have included the possible bias introduced by the time difference between the two cohorts (1997 versus 2001), which coincided with improvements in the treatment of advanced lung cancer.

Not all studies investigating the effect of multidisciplinary management on cancer outcomes have been positive, with some demonstrating conflicting results. A large observational study of more than 9,000 patients in the US revealed that there was little evidence that physician involvement in tumor boards improved overall survival in lung and colorectal cancer, although there were a number of limitations to this analysis. ${ }^{25}$ In this study, higher mortality was observed in patients who were discussed at MDMs where multiple cancers were discussed compared to MDMs where a single cancer type was discussed, suggesting that MDMs may result in a dilution of expertise in cancer management. ${ }^{25}$ There was however lower mortality observed in patients with extensive small-cell lung cancer and higher rates of curativeintent surgery offered in early stage NSCLC when physicians participated in weekly MDMs. These were clinical scenarios where combined modality treatment and optimal staging techniques are likely to provide greatest benefit. ${ }^{25}$ The authors concluded that MDM discussions should focus on complex cases where there is likely to be the most benefit from multidisciplinary care. ${ }^{25}$

\section{Other outcomes Diagnosis and staging}

It is crucial when lung cancer is suspected to obtain a tissue diagnosis to ascertain the tumor type and guide further investigation, management, and prognosis. Obtaining tissue can at times be a complex process and involve multiple specialties. Multidisciplinary care facilitates discussions between the different specialists involved in the diagnostic process to ensure that the site with the highest chance of obtaining tissue from is targeted first, thereby minimizing the risk to the patient of recurrent procedures. ${ }^{30}$ In lung cancer, access to specialist diagnostic investigations, including endobronchial ultrasound fine-needle aspiration, is important for accurate staging of lung cancer and delivery of appropriate treatment. ${ }^{21}$ There is evidence that access to the most accurate staging investigations is improved by multidisciplinary care. ${ }^{37,41}$ Indeed, multidisciplinary care improves the accuracy of tumor and nodal cancer staging, helping to limit unnecessary surgery, which does not appear to occur at the expense of patient undertreatment. ${ }^{37,41}$

\section{Treatment}

After tissue diagnosis and staging, treatment options for lung cancer may include surgery, chemotherapy, radiotherapy, supportive care, or combinations of these modalities. 
Multidisciplinary care helps to bring together the specialists required to deliver the most appropriate evidence-based treatment options for individual patients. Evidence has shown that MDM-based care is more likely to adhere to clinical guidelines and avoid variations in care. ${ }^{31,37,39,42}$ An MDM can be a vehicle for developing clinical governance, helping to deliver best-practice care and quality-improvement initiatives. ${ }^{43}$ Furthermore, there is the potential to streamline referrals and resources, ensuring less duplication of investigations and interventions. ${ }^{32}$

Timeliness of treatment delivery is one of the key performance indicators of quality care in lung cancer, and there are a number of studies demonstrating that the multidisciplinary model improves time between diagnosis and initiation of treatment. ${ }^{17,44}$ Timely treatment is considered particularly important in lung cancer, as tumors have rapid doubling times and delays in treatment may result in upstaging and worse outcomes for patients.

Selecting the most appropriate surgical procedure in early NSCLC is one of the most important steps in cancer management and vital to the individual patient's quality of care. A number of studies have demonstrated that multidisciplinary discussion leads to the correct procedure being undertaken for more patients and improved clinical decision making. ${ }^{45,46}$ Patients whose physicians attended weekly discussions at a tumor board were shown to be more likely to undergo curativeintent surgery in stage I and II NSCLC. ${ }^{25}$ As the overwhelming majority of long-term lung cancer survivors have early stage disease managed surgically, this quality indicator of treatment is likely to translate into improved survival.

Multidisciplinary care increases access to different treatment modalities in lung cancer, including surgery, chemotherapy, and radiotherapy, and facilitates recruitment into clinical trials. Patients with NSCLC stage I or II disease who have not received surgery have been shown to be more likely to receive radiotherapy if they have been discussed at a tumor board. ${ }^{47}$ Likewise, patients with stage IIIA NSCLC who were not treated surgically or had limited-stage small-cell lung cancer had a higher likelihood of optimal treatment with combined radiotherapy and chemotherapy if discussed at an MDT. ${ }^{47}$ Limited single-center data have shown that involvement in a multidisciplinary clinic improved enrollment in clinical trials..$^{25,48}$

\section{Patient-centered outcomes}

There is some evidence that patients are more satisfied and have better quality of life after receiving multidisciplinary care rather than the traditional model of care. ${ }^{23,44}$ It is possible that this improved satisfaction may be due to improved access to palliative care services. ${ }^{23,49}$ Palliative care has a key role for symptom management, as well as end-of-life care, and should be utilized early. Indeed, a randomized controlled study of early utilization of palliative care services versus standard care showed significantly improved quality of life, mood, and even survival in patients with advanced NSCLC. ${ }^{49}$ Another study showed that improved quality of life in lung cancer has in itself been linked to improved survival. ${ }^{50}$

\section{Communication and clinical decision making}

There are a number of important linking steps that must occur in a timely fashion to ensure best-quality care in lung cancer. These include correct processing of initial and subsequent referrals to specialists and timely and patient-centered treatment decisions, as well as supportive care, follow-up, and surveillance. Coordination of these processes is important for the patient's experience, and can be particularly difficult if the patient is from a rural or remote area. Communication of decisions is crucial to ensure smooth transition across health services and to avoid omission of any aspect of care It is thought that the multidisciplinary approach facilitates effective communication by ensuring that all members of the team are familiar with the patient's history and have been involved in formulating the treatment plan. Lamb et al performed a systematic review of 37 studies assessing the quality of care decisions emerging from MDMs, and demonstrated that discussion at an MDM changed management decisions in $2 \%-52 \%$ of cases. ${ }^{11}$ Furthermore, it was determined that the makeup of the MDT and a patient's psychosocial situation affected treatment decisions from cancer MDMs, emphasizing the importance of establishing leadership, team roles, and responsibilities in the multidisciplinary setting. ${ }^{11}$ One single-center study in the US showed that multidisciplinary discussion changed management decisions in $43 \%$ of breast cancer patients, including a number of cases where the treatment recommendation was changed from extensive to localized surgery. ${ }^{31}$ These results were replicated in a more recent retrospective study of breast cancer patients treated at a single-institution multidisciplinary clinic, which found that changes were made in the planned surgical management in $52 \%$ of cases discussed at the MDM. ${ }^{45}$

\section{Professional development}

Some have argued that discussions that occur in MDMs may not take into consideration factors that affect clinical practice in the real world. The evidence suggests, however, that there 
is respect among health professionals for decisions made at MDMs and that the recommendations are followed. One US study examined the outcomes of local MDMs and followed up patients to determine whether the recommendations of the MDT were implemented. ${ }^{51}$ It found that overall, $84 \%$ of treatment decisions made at MDMs were carried over into patient care. ${ }^{51}$

The medical professional's response to the model of multidisciplinary care is generally positive. In one review of Canadian general surgeons who attended MDMs, it was found that greater than $90 \%$ of respondents felt that the MDM ensured greater consideration of all patient-treatment options, facilitated multidisciplinary care, and improved communication with colleagues. ${ }^{52}$ Additionally, $85 \%$ felt that the MDM process contributed to their professional development, and more than half felt that it improved patient outcomes. ${ }^{52}$ On the strength of the evidence presented herein, discussion at an MDM, despite limited data for their effectiveness, has in itself become a measure of quality of care. ${ }^{12,15,16}$

\section{Barriers to success}

There are multiple barriers to successful multidisciplinary care. These include lack of dedicated or protected time for clinicians to attend, financial compensation, administrative support, appropriate and available venue space, and difficulties with communication, and record keeping. ${ }^{8}$ Adequate coordination of care can be difficult if the roles and responsibilities of each member of the MDT are not well defined, there are suboptimal referral processes in place, and communication between health care professionals is not adequately funded. ${ }^{53}$ Additionally, in some countries, such as Australia, there is a particular issue in rural and regional areas, where caseloads may be small and there is minimal or no funding to run MDM-based care. ${ }^{28}$ This issue has also been highlighted in Canada, where one of the major barriers to a successful multidisciplinary approach was the paucity of specialists in community hospitals. ${ }^{27}$

Administrative support is crucial to the effective and efficient running of MDMs and the smooth coordination of patient care. Wright et al found that a major barrier to the success of MDMs in Canada was the lack of an administrative coordinator. In this study, it was found that only $18 \%$ of community hospital MDMs and $57 \%$ of academic center MDMs had administrative support. ${ }^{52}$ It is clear that lack of administrative support means that team members have to take on MDM organizational roles in addition to their usual workload, and that this is a barrier to effective multidisciplinary care..$^{52,54,55}$
Attendance at MDMs is a serious issue, and has been addressed in a number of studies. ${ }^{46,54}$ In the UK, it was found that making the multidisciplinary sessions protected clinical time improved attendance, particularly for medical oncologists. Although clinical practice guidelines have been altered to highlight the importance of providing clinicians with protected MDM time, few health services have to date implemented this recommendation. ${ }^{54,56,57}$ The issue of supporting doctors to attend MDMs and remunerating them appropriately is an important measure to improve attendance at MDMs. Australia has implemented billing codes for attendance at MDMs to address this issue in an effort to encourage participation and sustainability. ${ }^{9}$ Eligibility for these billing codes requires at least four medical practitioners attending the MDM, proper record keeping, a discussion of approximately 10 minutes for each patient, and communication of the results of the MDM to the patient and primary care doctor. ${ }^{9}$

Medicolegal concerns have been identified as a possible issue affecting multidisciplinary care, especially when there is disagreement between members of the MDT. ${ }^{27}$ Many MDM participants are unsure of the medicolegal implications of participating in MDMs; in particular, they are often unaware that they have an individual liability for decisions made in an MDM. ${ }^{58}$ Sidhom and Poulsen examined physicians' perceptions about medicolegal responsibilities in Australian MDMs, and found that although there was often a significant amount of disagreement about patient-treatment decisions, this dissent was often not verbalized. ${ }^{58}$ The participants were not aware that they could be held responsible for decisions even if they did not necessarily agree with the final MDM recommendation if they were present at the meeting. ${ }^{58}$

\section{Conclusion}

Overall evidence suggests that multidisciplinary care facilitates the delivery of a high-quality lung cancer service, and that this may result in improved survival, guideline-based treatment, and quality of life for lung cancer patients. With the emergence of "personalized medicine", it is essential to define the standard of care in all aspects of lung cancer management. This extends from the process of obtaining a tissue diagnosis to staging and implementation of evidencebased treatment. An important component of best-quality lung cancer care is offering a service that provides equitable and timely access to diagnostic procedures and treatments, including emerging molecular therapies and enrollment in clinical trials.

While multidisciplinary care has emerged as the standard of care for lung cancer management, there remains a 
relative lack of data to justify the expense and time required to deliver this model of care. This review has outlined the available evidence that multidisciplinary care improves quality of life and survival, facilitates more accurate staging and appropriate treatment decisions, reduces ineffective surgical interventions, and increases assess to surgery, radiotherapy, and palliative care services. Additionally, physicians appear to be satisfied with the process, and feel that it provides the best-quality care for patients. Future research should focus on defining barriers to successful multidisciplinary care, including the role of clinical leadership and communication in facilitating care, and identifying existing administrative, logistic, time, and economic constraints on MDTs.

Ideally, MDMs function to help reduce variations in lung cancer care, particularly for complex patients who require multimodality treatment and for those from disadvantaged backgrounds or from rural and remote areas who may not have equality of access to cancer services. It is hoped that multidisciplinary care will overcome ageist and nihilistic attitudes to lung cancer and provide a standard of care that helps to improve outcomes, particularly survival. With the aging population and widespread introduction of lung cancer screening, in future MDMs will need to provide patientcentered and economically responsible clinical decision making in the setting of increased demand on health services. It is hoped that multidisciplinary care will fulfill these expectations and be a key player in improving outcomes in lung cancer, but there is work to be done in developing and refining the multidisciplinary care process.

More quality evidence is needed to confirm the association between multidisciplinary care and improvement in important lung cancer outcomes that so far have been demonstrated by limited observational data.

\section{Disclosure}

The authors report no conflicts of interest in this work.

\section{References}

1. Australian Institute of Health and Welfare. Lung Cancer in Australia: An Overview. Canberra: AIHW; 2011.

2. US Cancer Statistics Working Group. United States Cancer Statistics (USCS): 1999-2012 incidence and mortality web-based report. Available from: https://nccd.cdc.gov/uscs. Accessed December 17, 2015.

3. Cancer Research UK. Lung cancer statistics. 2012. Available from: http://www.cancerresearchuk.org/health-professional/cancer-statistics/ statistics-by-cancer-type/lung-cancer. Accessed September 3, 2015.

4. World Health Organization. Cancer: fact sheet 297. Available from: http:// www.who.int/mediacentre/factsheets/fs297/en. Accessed December 17, 2015.

5. Australian Institute of Health and Welfare. Cancer Survival and Prevalence in Australia: Period Estimates from 1982 to 2010. Canberra: AIHW; 2012.
6. Horton R. GBD 2010: understanding disease, injury, and risk. Lancet. 2012;380:2053-2054.

7. Bydder S, Nowak A, Marion K, Phillips M, Atun R. The impact of case discussion at a multidisciplinary team meeting on the treatment of survival of patients with inoperable non-small cell lung cancer. Intern Med J. 2009;39:838-841.

8. Fleissig A, Jenkins V, Catt S, Fallowfield L. Multidisciplinary teams in cancer care: are they effective in the UK? Lancet Oncol. 2006; 7:935-943.

9. Cancer Australia. All about multidisciplinary care. Available from: http://canceraustralia.gov.au/clinical-best-practice/multidisciplinarycare/all-about-multidisciplinary-care. Accessed December 17, 2015.

10. Forrest L, McMillan D, McArdle C, Dunlop D. An evaluation of the impact of a multidisciplinary team, in a single centre, on treatment and survival in patients with inoperable non-small-cell lung cancer. $\mathrm{Br} J$ Cancer. 2005;93:977-978.

11. Lamb B, Brown K, Nagpal K, Vincent C, Green J, Sevdalis N. Quality of care management decisions by multidisciplinary cancer teams: a systematic review. Ann Surg Oncol. 2011;18:2116-2125.

12. Gouveia J, Coleman M, Haward R, et al. Improving cancer control in the European Union: conclusions from the Lisbon round-table under the Portuguese EU presidency, 2007. Eur J Cancer. 2008;44:1457-1462.

13. American College of Surgeons. Cancer Program Standards: Ensuring Patient-Centered Care. Chicago: ACS; 2006.

14. Commission on Cancer. Cancer Program Standards 2012: Ensuring Patient-Centred Care. Version 1.0. Chicago: American College of Surgeons; 2011.

15. National Institute for Health and Care Excellence. Lung Cancer in Adults. London: National Institute for Health and Care Excellence; 2012.

16. National Comprehensive Cancer Network. NCCN guidelines: non-small-cell lung cancer. Available from: http://www.nccn.org/ professionals/physician_gls/f_guidelines.asp. Accessed September 3, 2015.

17. Salomaa E, Sällinen S, Hiekkanen H, Liippo K. Delays in the diagnosis and treatment of lung cancer. Chest. 2005;128:2282-2288.

18. Haque N, Raza A, McGoey R, Boulmay B, Diethelm L, Kantrow S. Small cell lung cancer: time to diagnosis and treatment. South Med J. 2012;105:418-423.

19. Davison A, Eraut C, Haque A, et al. Telemedicine for multidisciplinary lung cancer meetings. J Telemed Telecare. 2004;10:140-143.

20. Mitchell PL, Thursfield VJ, Ball DL, et al. Lung cancer in Victoria: are we making progress? Med J Aust. 2013;199:674-679.

21. Navani N, Nankivell M, Lawrence DR. Lung cancer diagnosis and staging with endobronchial ultrasound-guided transbronchial needle aspiration compared with conventional approaches: an open-label, pragmatic, randomised controlled trial. Lancet Respir Med. 2015;3:282-289.

22. Earle CC. Outcomes research in lung cancer. J Natl Cancer Inst Monogr. 2004:56-77.

23. Griffin J, Koch K, Nelson J, Cooley M. Palliative care consultation, quality-of-life measurements, and bereavement for end-of-life care in patients with lung cancer: ACCP evidence-based clinical practice guidelines. Chest. 2007;132:404S-422S.

24. Griffith C, Thurner J. United Kingdom National Health Sevice, Cancer Services Collaborative "Improvement Partnership": redesign of cancer services - a national approach. Eur J Surg Oncol. 2004;30 Suppl $1: 1-86$.

25. Kehl KL, Landrum MB, Kahn KL, Gray SW, Chen AB, Keating NL. Tumor board participation among physicians caring for patients with lung or colorectal cancer. J Oncol Pract. 2015;11:e267-e278.

26. National Breast Cancer Centre. Multidisciplinary Meetings for Cancer Care: A Guide for Health Service Providers. Sydney: NBCC; 2005.

27. Wright F, De Vito C, Langer B, Hunter A. Multidisciplinary cancer conferences: a systematic review and development of practice standards. Eur J Cancer. 2007;43:1002-1010.

28. National Breast and Ovarian Cancer Centre. Multidisciplinary Cancer Care in Australia: A National Audit 2006. Sydney: NBOCC; 2008. 
29. National Lung Cancer Working Group. Lung Cancer Multidisciplinary Meeting Toolkit. Wellington: Ministry of Health; 2014.

30. Gaga M, Powell C, Schraufnagel D, et al. An official American Thoracic Society/European Respiratory Society statement: the role of the pulmonologist in the diagnosis and management of lung cancer. Am J Respir Crit Care Med. 2013;188:503-507.

31. Chang J, Vines E, Bertsch H, et al. The impact of a multidisciplinary breast cancer center on recommendations for patient management: the University of Pennsylvania experience. Cancer. 2001;91:1231-1237.

32. Ruhstaller T, Roe H, Thürlimann B, Nicoll J. The multidisciplinary meeting: an indispensable aid to communication between different specialties. Eur J Cancer. 2006;42:2459-2462.

33. Butow P, Harrison J, Choy E, Young J, Spillane A, Evans A. Health professional and consumer views on involving breast cancer patients in the multidisciplinary discussion of their disease and treatment plan. Cancer. 2007;110:1937-1944.

34. Sainsbury R, Haward B, Rider L, Johnston C, Round C. Influence of clinician workload and patterns of treatment on survival from breast cancer. Lancet. 1995;345:1265-1270.

35. Junor E, Hole D, Gillis C. Management of ovarian cancer: referral to a multidisciplinary team matters. Br J Cancer. 1994;70:363-370.

36. Birchall M, Bailey D, King P. Effect of process standard on survival of patients with head and neck cancer in the south and west of England. Br J Cancer. 2004;91:1477-1481.

37. Stephens MR, Lewis WG, Brewster AE, et al. Multidisciplinary team management is associated with improved outcomes after surgery for esophageal cancer. Dis Esophagus. 2006;19:164-171.

38. Davis S, Dahlberg S, Myers M, Chen A, Steinhorn S. Hodgkin's disease in the United States: a comparison of patient characteristics and survival in the Centralized Cancer Patient Data System and the Surveillance, Epidemiology, and End Results Program. J Natl Cancer Inst. 1987;78:471-478.

39. Morris E, Haward RA, Gilthorpe MS, Craigs C, Forman D. The impact of the Calman-Hine report on the processes and outcomes of care for Yorkshire's colorectal cancer patients. Br J Cancer. 2006;95:979-985.

40. Coory M, Gkolia P, Yang IA, Bowman RV, Fong KM. Systematic review of multidisciplinary teams in the management of lung cancer. Lung Cancer. 2008;60:14-21.

41. Davies AR, Deans DA, Penman I, et al. The multidisciplinary team meeting improves staging accuracy and treatment selection for gastroesophageal cancer. Dis Esophagus. 2006;19:496-503.

42. Abraham NS, Gossey JT, Davila JA, Al-Oudat S, Kramer JK. Receipt of recommended therapy by patients with advanced colorectal cancer. Am J Gastroenterol. 2006;101:1320-1328.
43. Nicholls S, Cullen R, O’Neill S, Halligan A. Clinical governance: its origins and its foundations. Clin Perform Qual Health Care. 2000;8:172-178.

44. Gabel M, Hilton NE, Nathanson SD. Multidisciplinary breast cancer clinics: do they work? Cancer. 1997;79:2380-2384.

45. Newman E, Guest A, Helvie M, et al. Changes in surgical management resulting from case review at breast cancer multidisciplinary tumor board. Cancer. 2006;107:2346-2351.

46. Kee F, Owen T, Leathem R. Decision making in a multidisciplinary cancer team: does team discussion result in better quality decisions? Med Decis Making. 2004;24:602-613.

47. Keating NL, Landrum MB, Lamont EB, Bozeman SR, Shulman LN, McNeil BJ. Tumor boards and the quality of cancer care. J Natl Cancer Inst. 2013;105(2):113-121.

48. Magee L, Laroche C, GIlligan D. Clinical trials in lung cancer: evidence that a programmed investigation unit and a multidisciplinary clinic may improve recruitment. Clin Oncol (R Coll Radiol). 2001;13:310-311.

49. Temel JS, Greer JA, Muzikansky A, et al. Early palliative care for patients with metastatic non-small-cell lung cancer. $N$ Engl $J$ Med. 2010;363:733-742.

50. Ganz P, Lee J, Siau J. Quality of life assessment: an independent prognostic variable for survival in lung cancer. Cancer. 1991;67:3131-3135.

51. Petty J, Vetto M. Beyond doughnuts: tumor board recommendations influence patient care. J Cancer Educ. 2002;17:97-100.

52. Wright F, Lookhong N, Urback D, Davis D, McLeod R, Gagliardi A. Multidisciplinary cancer conferences: identifying opportunities to promote implementation. Ann Surg Oncol. 2009;16:2731-2737.

53. Walsh J, Harrison JD, Young JM, Butow PN, Solomon MJ, Masya L. What are the current barriers to effective cancer care coordination? A qualitative study. BMC Health Serv Res. 2010;10:132.

54. Macaskill EJ, Thrush S, Walker EM, Dixon JM. Surgeons' views on multidisciplinary breast meetings. Eur J Cancer. 2006;42:905-908.

55. Kelly MJ, Lloyd TD, Marshall D, Garcea G, Sutton CD, Beach M. A snapshot of MDT working and patient mapping in the UK colorectal cancer centres in 2002. Colorectal Dis. 2003;5:577-581.

56. Whelan JM, Griffith CD, Archer T. Breast cancer multi-disciplinary teams in England: much achieved but still more to be done. Breast. 2006; 15:119-122

57. Bradley PJ, Zutshi B, Nutting CM. An audit of clinical resources available for the care of head and neck cancer patients in England. Clin Oncol (R Coll Radiol). 2005;17:604-609.

58. Sidhom MA, Poulsen M. Group decisions in oncology: doctors' perceptions of the legal responsibilities arising from multidisciplinary meetings. J Med Imaging Radiat Oncol. 2008;52:287-292.
Journal of Multidisciplinary Healthcare

\section{Publish your work in this journal}

The Journal of Multidisciplinary Healthcare is an international, peerreviewed open-access journal that aims to represent and publish research in healthcare areas delivered by practitioners of different disciplines. This includes studies and reviews conducted by multidisciplinary teams as well as research which evaluates the results or conduct of such teams or
Dovepress

healthcare processes in general. The journal covers a wide range of areas and welcomes submissions from practitioners at all levels, from all over the world. The manuscript management system is completely online and includes a very quick and fair peer-review system. Visit http://www.dovepress.com/testimonials.php to read real quotes from published authors. 